\title{
Félix Frías y el giro a los Orientes bolivianos de José Ballivián*
}

por

\section{Pol Colàs}

Universitat de Barcelona

Este texto analiza el proyecto llamado «católico-industrial» del intelectual argentino Félix Frías, enmarcado en el influyente liberalismo católico latinoamericano de mitad del siglo XIX, para la propagación del catolicismo sobre los pueblos indígenas, como medio necesario para el surgimiento del espíritu liberal entre los neófitos. Se sostiene que, dado su exilio en Bolivia y su cercanía a la Administración de José Ballivián (1841-1847), las nuevas políticas de integración de los Orientes bolivianos en el mercado interior del país llevadas a cabo por ese gobierno recibieron influencias del discurso de Frías y ejercieron peso sobre el mismo. Frías expresó su pensamiento fundamentalmente en dos obras, publicadas en 1844 y 1846. Ambas, junto con la prensa, el diario de debates, la legislación y algunos otros escritos menores constituyen las fuentes utilizadas en este artículo. A través de ellas podremos abordar la intertextualidad entre la obra de Frías y la política de Ballivián.

Palabras Clave: Bolivia; Frías; Ballivián; siglo XIX; Orientes; indígenas.

Cómo Citar Este Artículo / Citation: Colàs, Pol, "Félix Frías y el giro a los Orientes bolivianos de José Ballivián", Revista de Indias, LXXXI/283 (Madrid, 2021): 799-831. https://doi.org/10.3989/revindias.2021.023.

A inicios de la década de 1840, llegaron a Bolivia varios intelectuales argentinos, tales como Domingo de Oro, Bartolomé Mitre, Benjamín Villafa-

* Esta investigación se ha desarrollado en el marco del proyecto I+D HAR2016-77609-P, financiado por la Agencia Estatal de Investigación (Ministerio de Ciencia, Innovación y Universidades) y el Fondo Europeo de Desarrollo Regional.

Agradezco a los evaluadores sus comentarios que, sin duda, han permitido mejorar este artículo, así como a Marta Irurozqui y Pilar García Jordán, sus inestimables consejos.

${ }^{1}$ polcolas1994@gmail.com, ORCID iD: https://orcid.org/0000-0003-2012-189X 
ñe, Félix Frías, y el uruguayo Wenceslao Paunero². En su calidad de unitarios huyeron de la guerra civil en la Confederación Argentina, comandada por los federales de Juan Manuel de Rosas, y de la represión generalizada establecida por estos contra la oposición, tras la derrota unitaria en la fallida campaña del general Lavalle entre 1840 y $1841^{3}$. Fue en ese último año cuando accedió a la presidencia de Bolivia el General José Ballivián, gracias a haber formado redes clientelares sólidas ${ }^{4}$ y a participar en sendos golpes de Estado contra Andrés de Santa Cruz y José Miguel de Velasco. La victoria en la batalla de Ingavi fue el elemento que legitimó a Ballivián en el poder ${ }^{5}$ y le permitió aplicar su proyecto político con la intención de «sacar al país del atraso económico endémico» ${ }^{6}$.

Como presidente, Ballivián capitalizó a favor de su Administración el talento de los exiliados rioplatenses ${ }^{7}$ en un proyecto nacional para Bolivia que

${ }^{2}$ Chile y Bolivia fueron los destinos principales de este exilio, ya fuera por la estabilidad política del primero, ya por la tradicional hostilidad hacia Rosas del segundo. Véase Romero Carranza, 1995: 46 y Blumenthal, 2015.

3 Gelman, 2009: 121-144.

${ }^{4}$ Radicadas básicamente en los lugares donde ejerció algún mandato político en época del Mariscal Santa Cruz, como La Paz o Cochabamba. Véase Colàs, 2019.

${ }^{5}$ Gracias a esa victoria, fue considerado un nuevo «Padre de la Patria», habiendo conseguido la segunda independencia de Bolivia, esta vez de las manos del Perú. Se le dedicó una retahíla de versos por ese suceso, como los de Bustamante, 1853. Se sigue la consideración de que «Para asentar ese Ejecutivo que, sin regresar a la monarquía, poseyera la capacidad unitaria del orden mayestático, Ballivián construyó discursivamente su oferta de gobierno en torno a la victoria de Ingavi» (Irurozqui, 2018: 95. Véase también Colàs, 2021).

${ }^{6}$ Varias publicaciones de la época se hacen eco de la gravedad de la situación económica en Bolivia (Prudencio, 1842a; 1842b), que se ve confirmada por la historiografía (Peralta e Irurozqui, 2000: 43-44), dada la continuidad bélica en la Guerra de la Confederación, la revolución restauradora y la Guerra Peruano-Boliviana que finalizó en la paz de Puno (1842). En este sentido, el ejército absorbía una cantidad de recursos insostenible (Peralta e Irurozqui, 2000: 61, 80. Dalence, 1851).

${ }^{7}$ Ballivián heredó de Andrés de Santa Cruz su aversión personal por Juan Manuel de Rosas (Colàs, 2019), acrecentada por su apoyo a los unitarios frente a la facción presidencial y por la «influencia que en Bolivia ejercían sobre su presidente los unitarios exiliados, entre los que se contaba Félix Frías» (Sierra, 1956: 350). Además, Carrasco (1960: 112-113) considera a Ballivián como un personaje enamorado de la vida intelectual y que, además, al conocer la llegada de los exiliados, «le entusiasmaba esa juventud ardiente que se jugaba la vida combatiendo al despotismo». De ese modo, Ballivián, con contactos anteriores con la oposición a Rosas por su condición de enemigo, y por tanto con referencias del talento de estos exiliados, tuvo conocimiento de los argentinos personalmente y les dio sitio en la administración. En esa misma línea se expresa Blumenthal (2015: 265). No obstante, como se apuntó, no fue el único país que recibió a estos exiliados; desde Chile seguirían con su militancia unitaria personajes como Domingo Faustino Sarmiento (Soria, 1999) o Juan Bautista Alberdi 
pretendía romper el cerco altiplánico o su percepción como un espacio históricamente configurado en torno al altiplano y los valles periféricos ${ }^{8}$. Uno de sus objetivos era inundar el incipiente mercado interno y el creciente comercio internacional con los recursos naturales, supuestamente «abundantísimos», de los Orientes bolivianos 9 . Ese giro oriental marginaba la aventura de formar un puerto viable en las costas del Pacífico a través del fomento de las actividades económicas en el lejano puesto de Cobija o mediante la anexión del territorio peruano de Arica ${ }^{10}$ y proponía en su lugar utilizar la extensa red fluvial oriental de Bolivia para llegar al Atlántico por el Pará o por el Plata $\mathrm{y}$, desde allí, conectarse con el mercado mundial ${ }^{11}$.

Tales afirmaciones contrastan con la percepción de la figura de Ballivián de la historiografía tradicional. Mientras para Gabriel René-Moreno, el «mando que Ballivián codiciaba con sed rabiosa» fue su obsesión, «que ejerció dictatorialmente hasta cuando más no pudo» ${ }^{12}$; Alcides Arguedas lo consideró un político y militar irresponsable, incompetente, autoritario y de una inteligencia cuestionable, aunque por encima de sus iguales, dado el bajo nivel cultural de los miembros del ejército ${ }^{13}$. Estos ejemplos de la «narrativa de la nación enferma» ${ }^{14}$ respondían, como se ha indicado en trabajos críticos recientes $^{15}$, entre otras razones, a una relectura legitimadora del nuevo orden político de las últimas décadas del siglo XIX que justificaba su naturaleza refundadora de la República mediante la defenestración del periodo anterior,

(Botta, 2013. Serrafero, 2016), paralelamente a recibir exiliados bolivianos como el propio Andrés de Santa Cruz (Crespo, 1997: 63-66).

${ }^{8}$ La República Boliviana nació con un conocimiento paupérrimo de sus tierras orientales; no obstante, durante la presidencia de José Ballivián (1841-1847) se pretendió llevar a cabo un plan para la ocupación y control de esos territorios, como destaca García Jordán, 2001: 251-252.

${ }_{9}$ La presencia de riquezas sin parangón en los Orientes de Bolivia fue un discurso recurrente y de creciente importancia, alimentado por los viajes, exploraciones y expediciones de personajes como d'Orbigny, 2004 o Palacios, 1852: 1-2.

${ }^{10}$ Las ventajas y los inconvenientes de cada puerto para Bolivia han sido expuestos en Fifer, 1972: 36-50; mientras que podemos encontrar datos específicos del puerto de Cobija en las obras fundamentales de Cajías, 1975 o Lofstrom, 1974, así como en Cajías, 1997. Borie, Castro, Varela y Aldunate, 2016: 221-222. O Letelier Cosmelli, 2016: 232-233.

${ }_{11}$ Para ello, el control administrativo del Estado sobre los Orientes era indispensable, siendo uno de los motivos que llevaron a la erección del departamento del Beni en 1842 (Groff Greever, 1987: 31-43. Guiteras Mombiola, 2012: 28-29).

12 René-Moreno, 1970: 14.

13 Arguedas, 1967: 115.

14 Véase Paz Soldán, 2003.

15 Deben destacarse los siguientes trabajos. Peralta, 1992. Irurozqui, 2000: 39. Roniger y Herzog, 2000: 5. Morelli, 2004: 759. 
el llamado «caudillista» ${ }^{16}$. Autores canónicos como los citados contribuyeron a la formación de un discurso que homogeneizó a los gobernantes bolivianos anteriores a la Guerra del Pacífico en la perfidia y mediocridad administrativa, lo que ha invisibilizado y degradado sus políticas gubernamentales. José Ballivián, en concreto, inauguró la búsqueda de la solución a la mediterraneidad de Bolivia en los Orientes, como se ha apuntado; sin embargo, hasta la fecha solo hay un trabajo dedicado a ello y menciones en estudios dedicados a las Tierras Bajas ${ }^{17}$. En ese único texto, se anuncian las influencias de Félix Frías sobre el poliédrico proyecto de Ballivián, aunque sin demostrarlo empíricamente, lo que se ha querido paliar con este trabajo; en el trabajo presente no se persigue restituir la figura del político, sino propiciar una revisión historiográfica que matice el discurso arguediano de inmovilidad e incompetencia políticas, destacando un trasfondo filosófico notable tras las obras de su Gobierno.

En concreto, a partir del contexto de revisión historiográfica y reconfiguración territorial de Bolivia, se propone el estudio de la figura y obra de Félix Frías. Salido de Buenos Aires en 1839 para luchar en la Banda Oriental contra Juan Manuel de Rosas, su militancia unitaria lo llevó al exilio con la muerte del General Juan Lavalle ${ }^{18}$, primero en Bolivia, donde entró en contacto con el círculo de intelectuales que rodeaban a José Ballivián en la hacienda de Cebollullo, después en Chile, como enviado comercial boliviano. Miembro de la Generación del 1837, con Alberdi y Sarmiento como figuras destacadas, es considerado el más conservador de estos y un acérrimo defensor del catolicismo ${ }^{19}$. En este sentido, el prestigio de Frías fue aprovechado por Ballivián quien se convirtió en mecenas de nuestro personaje, como también de varios de sus compañeros de exilio, a quienes ayudó tanto en la publicación del periódico La Época, que ellos mismos fundaron, como proporcionándoles empleos diplomáticos con incidencia en la esfera pública ${ }^{20}$.

$\mathrm{Su}$ experiencia transnacional le permitió componer una obra panamericanista que compatibilizaba el catolicismo, del que participaban todas las repúblicas hispanoamericanas, con el pensamiento liberal, con el objetivo de propiciar el progreso nacional o la civilización, ideario enmarcado entre múltiples propues-

16 Por ello, siguiendo las tesis defendidas por Irurozqui, 2018: 19, siendo el caudillismo tomado como un término histórico con una carga peyorativa intrínseca, se omite su uso en este artículo.

${ }^{17}$ Además del de Groff Greever, 1987, encontramos las menciones expresas de García Jordán, 2001. O Guiteras Mombiola, 2012. O Lema Garrett, 2016.

${ }_{18}$ Castelfranco, 2018; 2019: 317.

19 Grinchpun, 2015: 1-2.

${ }^{20}$ Carrasco, 1960: 114-115. 
tas de ese tipo en la época, constituyéndose en una más ${ }^{21}$. Sin embargo, para el caso concreto de Bolivia, Frías proponía como vía consecutora de su progreso la colonización y evangelización de los Orientes, una propuesta concreta y práctica con la que trató de influenciar la opinión pública boliviana ${ }^{22}$ a través de redes de sociabilidad intelectual transfronterizas, como se ha estudiado para su etapa en Francia ${ }^{23}$, pero no para su estadía boliviano-chilena.

En definitiva, el objetivo de este artículo es analizar las conexiones entre el pensamiento «católico-industrial» de Félix Frías aplicado a las tierras «no civilizadas» de la América decimonónica y el «giro a los Orientes» desarrollado durante la presidencia de Ballivián. Para ello el texto se organiza en tres partes. En la primera, se caracteriza la figura de Frías y su obra y se la introduce en el marco temporal y político de la Latinoamérica - y la Bolivia - de la década de 1840, para así, en la segunda, poder ofrecer una reconstrucción del pensamiento de Frías a partir de dos de sus textos fundamentales, «El cristianismo católico considerado como elemento de civilización en las repúblicas hispano-americanas» publicado en 1844 en Valparaíso y la Nota dirijida a S.G. el señor Don Tomás Frías..., editada en Sucre en 1846. Ambos escritos serán analizados teniendo en cuenta su representación discursiva y su subjetividad implícita ${ }^{24}$. En la tercera parte, se abordará la intertextualidad entre las ideas de Frías, la legislación producida bajo el mandato de José Ballivián, los proyectos políticos y las acciones gubernativas desarrolladas en los Orientes bolivianos y las respuestas expresadas públicamente por el Con-

${ }^{21}$ Sobre la compatibilidad de, por un lado, el liberalismo (y la modernidad, civilización, secularización) y por otro, la religión, Maiguashca (2005: 258) insiste en la necesidad de romper la presunción de ser términos excluyentes. Hablando del presidente ecuatoriano Gabriel García Moreno, destaca como «para García Moreno el Estado no solo debía proteger al catolicismo, sino que debía también transformarlo en un paradigma normativo con respecto al cual se debían medir otras definiciones del bien social» (Maiguashca, 2005: 257). Conjunción entre liberalismo y catolicismo que se pretendió en toda la geografía americana, con casos destacados como en Colombia (Plata Quezada, 2009: 73) o Perú (García Jordán, 1991), o en la antigua metrópolis (Capellán de Miguel, 2000. De Vicente Algueró, 2012). En ese tipo de proyecto, pero con un marco territorial diferenciado como objetivo, los Orientes, se enmarca el de Félix Frías.

22 Entendiendo opinión pública como lo comprendido en el espacio público, la «red para la comunicación de contenidos y tomas de postura» (Habermas, 1998: 440) característica de la sociedad moderna.

${ }^{23}$ Castelfranco (2019) lleva a cabo un estudio sobre las relaciones intelectuales de Frías en Francia entre 1848 y 1855, cuando estructuró «un lenguaje ultramontano y conservador» ciertamente de una mayor radicalidad del mostrado entre 1841 y 1847.

${ }^{24}$ En contraposición a la objetividad que atañe al texto legislativo (Chartier y Sanchís Martínez, 1991: 165-171). 
greso o la prensa haciendo tangible la comunicación entre la obra de Frías y las prácticas políticas gubernamentales.

\section{FÉLIX Frías en SU CONTEXTo}

En época de asentamiento del liberalismo económico y político en la Latinoamérica independiente y de construcción de realidades fundacionales de los nuevos Estados, hubo intelectuales, con el argentino Domingo Faustino Sarmiento como uno de los más destacados, que trataron de moldear el proceso según sus aforismos ideológicos ${ }^{25}$. Félix Frías se enmarcó entre ellos ${ }^{26}$ con un pensamiento conservador que pretendió fundir la religión cristiana católica con el progreso industrial, un liberalismo católico en la línea del espíritu reformador defendido por el francés Lamennais a principios de $\operatorname{siglo}^{27}$, siguiendo preceptos surgidos de la Revolución Francesa. Aunque fue un ideario combatido por la Iglesia oficial ${ }^{28}$, Frías se convirtió en uno de los mayores defensores de esa vía ${ }^{29}$. En realidad, la particularidad de su proyecto católico-industrial, que de otro modo hubiera sedimentado en el devenir histórico como uno más de los existentes, fue la centralidad de las Tierras Bajas americanas en su discurso. Sobre todo, y específicamente, las de Bolivia, suponían una panacea por descubrir, un mundo de riquezas ilimitadas por construir; algo que, como se verá en este artículo, solo podía suceder a partir de la transmisión de valores católicos — «civilizatorios» por extensión- a los habitantes de esos Orientes. La cercanía con el propio José Ballivián durante su exilio, abierto a recibir talento foráneo en su círculo de Cebollullo ${ }^{30}$, le llevó a plasmar su ideal social en dos folletos políticos y variados artículos de prensa, para tratar de influir con ellos ${ }^{31}$ en las políticas orientalistas que la Administración boliviana había inaugurado ${ }^{32}$.

25 Myers, 2004: 172.

${ }^{26}$ Encontrándose en conexión constante con estos, por razones políticas y geográficas, sobre todo con los intelectuales argentinos unitarios (Blumenthal, 2015. Castelfranco, 2018).

${ }^{27}$ Aubert, Beckmann, Corish y Lill, 1981: 47. Los franceses Lamennais y su discípulo Lacordaire fueron ampliamente difundidos por América Latina, y tomados sus textos como modelos del liberalismo católico defendido por Frías y cantidad notable de autores latinoamericanos (Myers, 2004: 163. Ayala Mora, 2008: 267).

28 Tanto el Papado como las estructuras eclesiásticas propias de Latinoamérica (Ayala Mora, 2008: 266-268).

29 Junto con otros miembros de esta por todo el continente, como el citado ecuatoriano García Moreno (Maiguashca, 2005) o José Ignacio Víctor Eyzaguirre en Chile (Méndez Reyes, 2006: 297).

${ }^{30}$ Carrasco, 1960: 121.

31 Véase Blumenthal, 2015: 265.

32 Carrasco, 1960: 114. Groff Greever, 1987: 202-203. 
Frías animó a participar a los exiliados rioplatenses, como De Oro o Paunero, en los debates abiertos en el país, incentivándolos a convertirse en un arma de la causa ballivianista y obtener, así, un soporte institucional para sus obras y folletos que el propio Estado se encargaría de difundir ${ }^{33}$. Su activa participación en la política del momento le llevó a ser nombrado encargado de negocios de Bolivia en Chile. Este cargo le permitió tomar parte de los debates filosóficos y políticos chilenos con publicaciones variadas $\mathrm{y}$, al mismo tiempo, seguir en contacto con su mecenas y estar al día de la opinión pública argentina y boliviana.

El proyecto de Frías se visibilizó en dos textos fundamentales que se analizarán en el siguiente acápite en detalle, bajo el argumento de expresar un pensamiento que se desarrolló en paralelo, se realimentó del proyecto orientalista de Ballivián e influyó en el mismo. Frías publicó en 1844 la obra «El cristianismo católico considerado como elemento de civilización en las repúblicas hispano-americanas» en Valparaíso. El sugerente título puntualiza la importancia de la religión - y en el caso de los indígenas no reducidos, la evangelización misionera - en la implantación del proyecto civilizatorio en América, una problemática tratada en varios trabajos actuales ${ }^{34}$. Su formulación fue debida a lo que percibió en el ambiente como intentos de «ostilizar $[$ sic] entre nosotros el sentimiento relijioso [sic] i los bienes sociales que de él emanan» ${ }^{35}$, ante los numerosos artículos de «fanáticos liberales» ${ }^{36}$ de los que ese libro pretende ser una contestación severa. Más concretamente, como el artículo «Sociabilidad chilena» de Francisco Bilbao «perturbó» la tranquilidad social y tuvo remarcable repercusión en Chile ${ }^{37}$, Frías se propuso formular una propuesta separada de la de Bilbao, que se centraba en conceptos polémicos como «soberanía popular» ${ }^{38}$, a partir de la reforma liberal de la

${ }_{33}$ Como lo demuestra el tono y las peticiones hechas a Domingo de Oro en su correspondencia. El 1846, estando este en Lima como enviado diplomático, el presidente le escribió señalando que «sería oportuno que usted escribiese un folleto, probando la necesidad, utilidad y ventajas que resultarían al país de su empréstito que diese animación y vida a nuestros elementos de prosperidad y ocupación a los hombres que no la tienen», un empréstito que, según parece, sería aceptado gracias a la influencia del argentino en la opinión pública, Carta de José Ballivián a Domingo de Oro, La Paz, 27 de octubre de 1846, Archivo Histórico de Bartolomé Mitre, Buenos Aires (ABM). La colección de correspondencia entre Domingo de Oro y José Ballivián se encuentra en este Archivo.

34 Véase García Jordán, 2001: 272-273. Langer, 1994a: 403; 2011: 178.

${ }^{35}$ Se mantiene la grafia original de las citas recogidas en el articulo.

${ }^{36}$ Frías, 1844: III-IV.

${ }^{37}$ Bilbao, Francisco, "La sociabilidad chilena", El Crepúsculo, Santiago de Chile, $1 / 6 / 1844$.

${ }^{38}$ Rojas Castro, 2014: 133. 
Iglesia $^{39}$. Debido a su insatisfacción con la recepción y el debate público en Bolivia provocado por esta primera obra y consciente de que su lejanía - se hallaba en Chile - dificultaba la circulación de ideas y su penetración en las diferentes esferas públicas a las que iban destinadas, Frías decidió volver a publicar sobre la problemática en cuestión y centrar su análisis en Bolivia. En la Nota dirijida a S.G. el señor Don Tomás Frías..., de 1846, en ese momento ministro de Relaciones Exteriores, autoridad superior directa en su condición de enviado comercial, ordenó las ideas de «El cristianismo católico» para facilitar su movimiento y las aplicó al caso boliviano.

\section{EL PROYECTO CATÓLICO-INDUSTRIAL}

En «El cristianismo católico», Frías sostiene como argumento central que la religión es un pilar indispensable para la civilización, el orden y el progreso de la sociedad ${ }^{40}$. Sin embargo, expone que la Iglesia americana, a la que califica de «atrasada», necesita una reforma «liberal» que la ponga al servicio del Estado en la propagación de la religión católica y que logre la conversión de toda tierra en industriosa y de progreso. Aunque la temática central del texto es el papel de la Iglesia, en estas páginas se fija la vista en la relación de su pensamiento con la obra del Estado y de la nueva política de apertura hacia los Orientes junto con la pretendida expansión del catolicismo.

Frías defiende que el catolicismo es el marco mental donde debe delimitarse el pensamiento, la moralidad y la acción de toda sociedad que aspire al progreso. Este va ligado al trabajo, la industria, cumbres de las necesidades humanas, considerando que «con la cruz i el arado tienen cuanto pueden apetecer para aspirar a los beneficios de la civilización $\gg{ }^{41}$. La religión permite conformar un caldo de cultivo sólido para la instauración de los ideales liberales de esa civilización concreta: la propiedad individual y la libertad individual $\mathrm{y}$, asimismo, la inquietud por el crecimiento económico, que se traduce en industria e inversión. Por ello, sostenemos que el proyecto «cató-

39 Sólo se pretende abordar tangencialmente el debate sobre la reforma liberal eclesiástica, que podría ser objeto por sí mismo de un artículo monográfico, pero es importante conocer la actitud crítica liberal-católica de Frías ante la Iglesia y, a su vez, de pretendidas reformas radicales de ésta como la propuesta por Francisco Bilbao.

${ }^{40}$ Concibe la posibilidad de la existencia de un pueblo ateo como tan imposible como la de uno literato y filósofo, ante lo que el catolicismo otorga un punto medio moral aceptable para la ciudadanía y para los más grandes filósofos en los que se espeja y se escuda en este sentido: Montesquieu, Rousseau y Lamartine. Frías, 1844: 6-18.

${ }^{41}$ Ibidem: 81. 
lico-industrial» de Frías unido a los ingredientes liberales, antes citados, conformaron su ideal social y fundamentaron su pensamiento. En su opinión, la absorción del cristianismo por una sociedad, en un primer paso, llevaría a la expansión del liberalismo y, con él, de la industria, en un segundo paso.

La relación entre cristianismo y trabajo, considera Frías, debía ser parte de la moralidad ciudadana, lo que solo podía proceder de una acción conjunta político-eclesiástica ${ }^{42}$. El fomento de la educación popular y religiosa útil permitiría convertir en reales los conceptos liberales de difusa aplicación en América, como la propiedad y el trabajo ${ }^{43}$ :

Los gauchos, los rotos, los guasos, los indios, esos millones de ombres qe [sic] forman la plebe americana, llamada por los principios de la revolución a la participación de los derechos políticos, al servicio del réjimen [sic] constitucional más perfecto, solo por la mano de la relijión [sic] cristiana podrán ser levantados a la altura moral, qe los aga [sic] capaces de la libertad republicana. Si queremos qe nuestro réjimen [sic] representativo sea algún día una realidad i no una farsa constitucional, depositemos pues las semillas religiosas [sic] en la educación popular, civilicemos nuestras cosas para que nuestras palabras dejen de representar una mentira $^{44}$.

Esa «plebe americana» de Frías, los indígenas «sin civilizar», maleducados y errantes por la falta de religión, debían ser el cuerpo de la nueva sociedad cristiana auténticamente liberal. La religión católica suponía el marco mental o doctrinal ideal que permitiría la asunción de los preceptos del liberalismo por la «plebe», de la mano del Estado y de una Iglesia que, consciente de su valor para la transformación social e ideológica, tomara su tarea como una oportunidad y no, como Frías veía que ocurría en ese momento, como una obligación legislativa. Para ello Frías consideraba necesaria una renovación «liberal» de la Iglesia, institución que asumía anacrónica en sus planteamientos, pero reformable si se ponía al servicio directo de las luces propias del siglo ${ }^{45}$.

42 Ibidem: 84.

${ }_{43}$ Algo que, como señala Irurozqui (2008: 71-74), iba en consonancia con el ideario de «virtud pública» y «educación cívica», del sufragio capacitado que se impuso en la primera mitad del siglo XIX en Bolivia a partir de la restricción del voto según modelos de civilización, capacitación personal y libertad de acción. El vínculo entre educación y progreso fue el motivo de las reformas liberales de la educación de final de siglo en Bolivia (Martínez, 1998: 20).

${ }^{44}$ Frías, 1844: 81-82.

45 Todo ello rompía en parte con la tradición reformista radical que inauguró el Mariscal Sucre en su relación con la Iglesia, suprimiendo el clero regular y separándolo del Estado (Lofstrom, 2011: 162-183), pero se mostraba partidario de la subordinación de la Iglesia a las necesidades del Estado, como el propio Sucre pretendió, de una forma más cercana a las políticas cordiales de Andrés de Santa Cruz o el propio José Ballivián (Lofstrom, 2011: 197208. Parkerson, 1984: 44). 
Sobrellevando la falta de sentimiento liberal en la Iglesia boliviana, para el argentino la única opción de llevar a cabo un proyecto como el suyo pasaba por aprovechar la oportunidad que suponía la ocupación oriental. Reconocía «inmensa la obra de educar para la libertad moderna a los pueblos sud-americanos», pero al mismo tiempo que «la revolución no puede retrogradar, tenemos fe ardiente en el porvenir democrático de estos países; i es por qe esperamos, qe nos abate i contrista en los ombres [sic] de intenciones liberales esa exajeración [sic] en los principios $\rangle^{46}$. Relacionaba, así, la inestabilidad política, la falta de referentes claros y la confusión ideológica con una falta de democracia solo remediable a partir de la incorporación de los pueblos indígenas a la civilización a través de la religión. Solo a través de ella podría conjurarse el peligro de la apocalíptica existencia de un camino reversible, ya que si estos tomaban «sus ideas sociales en la fuente impura de una filosofía irrelijiosa [sic], su entusiasmo innovador en vez de ser benéfico atizará el fuego de las preocupaciones coloniales i la contra-revolución ganará terreno» ${ }^{47}$. Frías sostenía que los pueblos indígenas eran un lienzo en blanco que debía ser manipulado con esmero.

En su Nota dirijida a S.G. el señor Don Tomás Frías..., de 1846, el argentino aborda directamente el caso boliviano pormenorizando las problemáticas principales que atañen al país y que le impiden su consolidación y crecimiento. Las soluciones que debía tomar la Administración de Ballivián en ese sentido eran la conquista de los Orientes para obtener la navegación fluvial que conectase al país con el Atlántico. Ello facilitaría el poblamiento de las Tierras Bajas con inmigrantes internos y externos, que, junto con el sometimiento de las poblaciones indígenas a partir de la propagación de la civilización, proveniente de la religión católica, darían lugar a un escenario de riqueza nacional ${ }^{48}$. Frías era consciente de que la Administración ballivianista ya se había movido en ese sentido, pero proponía una política continuista que profundizase las políticas orientalistas en el sentido católico-industrial que consideraba inexcusable imprimirles.

En referencia a la prioridad que debía tener la navegación fluvial para alcanzar el Atlántico conviene señalar que desde el surgimiento de Bolivia como república, sus gobernantes habían intentado, con escasos resultados, ya convertir el puerto de Cobija en un caladero de dimensiones aceptables, ya acceder a Arica, salida natural al Pacífico de la ciudad de La Paz, como puerto, cuestión a la que Perú se opuso, como veremos ${ }^{49}$. Frías, que sostiene que

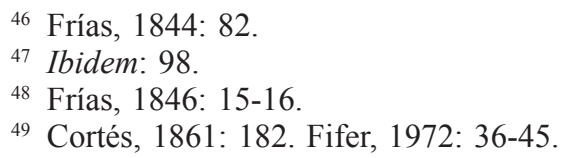


la riqueza del país dependía en gran medida de su capacidad de participar del comercio internacional, dice ser consciente de «las graves dificultades, con que tendría que luchar esa República [Bolivia] para elevarse a la altura de un país rico i poderoso, cuanto deben aspirar a serlo los nacientes estados de la América Española». En su opinión

... esas dificultades provenían principalmente de la viciosa demarcación de límites trazada por la mano victoriosa de Bolívar. I ciertamente es de deplorar, que ese jenio [sic] no hubiera previsto que la nación que fundaba, sin bastante frente al Pacífico, i sin comunicación con el Atlántico, quedaba reducida a una situación llena de embarazos para los progresos de su comercio i de su industria.

Según Frías, solo era preciso «echar una ojeada sobre el mapa de la América Meridional para advertir, que de todos los estados que la componen, ninguno se halla peor colocado que la República de Bolivia, si consideramos la parte de territorio, al que sus autoridades estienden [sic] su dominio i las vías actuales de su comercio» ${ }^{50}$.

Para Frías, Bolivia nació en condición de mediterraneidad, imposibilitando así conectarse al mercado internacional, fundamento de la riqueza de los pueblos, afirmaba. Pocos años antes, Julián Prudencio ${ }^{51}$ consideraba justamente lo contrario: que la entrada masiva de productos extranjeros baratos estaba destruyendo la industria nacional y que ese encierro era necesario para la creación de un mercado interno con fuerza suficiente para competir con el extranjero $^{52}$. Si bien se aplicaron políticas proteccionistas con los presidentes Santa Cruz, Velasco y Ballivián ${ }^{53}$, estas no fueron tanto dirigidas a la protección de la industria como al fomento del crecimiento del puerto de Cobija ${ }^{54}$. Cuando se vio que ello era poco factible, la idea de la necesidad de superar una mediterraneidad boliviana «maldita» propuesta por Frías ${ }^{55}$ pasó a ser la fundamental en el ideario comercial del Estado boliviano y superó a la de la necesidad de un encierro progresivo bajo la protección estatal propuesta por Prudencio.

${ }^{50}$ Frías, 1846: 1-2.

${ }^{51}$ Abogado chuquisaqueño, fue un personaje influyente durante la presidencia de Ballivián que trató de liderar, desde sus escritos, una respuesta proteccionista de la opinión pública contra el cada vez más dominante librecambismo. Véase Demélas, 1992: 321 y Peralta e Irurozqui, 2000: 43-45.

52 Prudencio, 1842b: 5.

${ }^{53}$ Huber Abendroth, 1997: 10. Platt, 2016: 79.

${ }^{54}$ Siendo considerado necesario un proteccionismo terrestre, es decir, por las fronteras de tierra, básicamente las del Titicaca con el Perú (Fifer, 1972: 48).

${ }_{55}$ El propio Frías (1846: 2) describe la condición mediterránea de Bolivia como una maldición de difícil solución, como se extrae de las citas expuestas en este apartado. 
Frías postula la conexión atlántica en detrimento de la pacífica. Sostenía que Cobija era un puesto inservible, ya que los «datos estadísticos que recientemente ha publicado el Restaurador sobre el puerto La-Mar, demuestran sin necesidad de comentario que no habría esfuerzo suficiente para sacar a esa población de sus mezquinas proporciones actuales». Asimismo, la experiencia había mostrado que «el Perú no consentirá jamás en ceder parte de su territorio a pretensiones apoyadas en las armas; i además las rivalidades nacidas de las continuas luchas entre ambos países i el celo exajerado [sic] de los pueblos americanos en favor de su integridad territorial, advierten del mal éxito que tendrían demandas $\rangle^{56}$ como la cesión de Arica, ya fuera por vía militar, como trató de conseguir Santa Cruz con la creación de la Confederación Perú-Boliviana ${ }^{57}$ y Ballivián en su campaña contra el Perú después de Ingavi $i^{58}$; o por vía diplomática, como intentó a través de Domingo de Oro en Lima $^{59}$. Y aun en el caso de conseguir la cesión del puerto de Arica, salida natural de los bienes paceños y cochabambinos ${ }^{60}$, Frías opinaba que este «tampoco satisfaría otras necesidades que las del solo departamento de la Paz, nada a propósito por su posición al pie de la cordillera i sobre las fronteras del norte para servir de mercado a los otros puntos de la República» ${ }^{61}$. Es decir, la conexión con el mercado mundial a través del Pacífico era una pérdida de recursos y tiempo para Bolivia, por los encadenados fracasos por ampliar la zona costera por cualquier vía y por la lejanía y presencia de los Andes y el desierto. Por el contrario, Frías considera fundamental la conexión por el Atlántico:

Bolivia debe apartar su vista del Pacífico, pues no es del mar de donde ha de venir su porvenir comercial. Ese porvenir ha de nacer por el oriente. El Gobierno de Bolivia, dominado por una política sabia i previsora, así lo comprendió desde los primeros días de su elevación al poder; y los esfuerzos perseverantes consagrados a la realización más o menos próxima de tan alto pensamiento, son los más bellos timbres de S.E. el Presidente de la República, i han sido aplaudidos justamente por los que se interesan en el feliz éxito de las empresas verdaderamente útiles a los pueblos americanos ${ }^{62}$.

56 Frías, 1846: 2.

57 Sobrevilla Perea, 2011: 142. Colàs, 2019.

${ }^{58}$ Al finalizar la invasión peruana de Bolivia, trató de llevar la guerra al Perú, tomando Arica. Véase Ballivián, 1841.

59 Véase Francisco Zaballo (Domingo de Oro) a José Ballivián, 11 de abril de 1845, ABM. Consúltese también Carrasco, 1960: 116 y Groff Greever, 1987: 202.

${ }^{60}$ Barragán, 2009: 42.

${ }^{61}$ Frías, 1846: 2-3.

62 Ibidem: 3. 
Frías conocía la voluntad de José Ballivián y su gobierno para mutar en su objetivo, girar completamente su visión centrada en la difícil salida al mar por el desierto de Atacama y centrar su atención en los casi desconocidos Orientes. Las numerosas vías fluviales existentes en los Orientes permitirían una conexión directa por el Madera-Amazonas y el Paraguay con el Atlántico, donde existía la verdadera riqueza que entrañaba el comercio internacional. De ahí el interés gubernamental por patrocinar y financiar expediciones de exploración y navegación de ríos como el Pilcomayo, el Bermejo o el Beni ${ }^{63}$. Estas expediciones, juntamente con la creación del departamento del Beni en $1842^{64}$, fueron los primeros indicadores del giro en la política del Ejecutivo relativa a sus conexiones internacionales.

Este giro era para Frías inevitable. La geografía de Bolivia fue trazada por él como una división en tres regiones claras. La primera, la occidental y con acceso al Pacífico - es decir, el distrito Litoral—, no permitía una agricultura funcional, esto es, no albergaba la población suficiente para la creación y sustento de un puerto costero que satisficiese las necesidades comerciales de Bolivia, citando las minas de guano y cobre como elementos a tener en cuenta, pero que no podrían cambiar esa realidad ${ }^{65}$. La segunda, la del centro, liderada por el departamento de La Paz, con los de Tarija, Potosí, Cochabamba, Chuquisaca y Oruro, «aunque provistos de todos los productos destinados a satisfacer las necesidades físicas del hombre, i que abundan en sus valles, no han sido sin embargo tan favorecidos por la naturaleza que puedan sostener la industria agrícola, la verdadera industria americana», exceptuando la importancia de la cascarilla o quina en La Paz, o las minas ${ }^{66}$. En relación con esto último, mientras la primera, recurso natural de gran éxito en el mercado europeo por sus propiedades medicinales, se encontraba en pleno auge ${ }^{67}$, la segunda impedía el crecimiento real — esto es, agrícola e industrial— pues

${ }^{63}$ A destacar el Diario de navegación del río Pilcomayo por el General Manuel Rodríguez Magariños, 1844 y el Informe de viaje de Enrique N. Van Nivel por el río Pilcomayo, 1844, ambos disponibles en el Archivo de la Casa de la Libertad, Sucre. También debe destacarse la expedición de Palacios (1852), llevada a cabo en el Departamento del Beni.

${ }^{64}$ Guiteras Mombiola, 2012: 29.

${ }^{65}$ Frías, 1846: 4. Abrir nuevas minas en Latinoamérica en la primera mitad del siglo XIX se estaba demostrando una tarea casi imposible por la falta de capitales y la timidez en la inversión demostrada por los industriales de Europa, básicamente Gran Bretaña. Véase Halperin Donghi, 2013 y Bulmer-Thomas, 1998.

${ }^{66}$ Frías, 1846: 4.

${ }^{67}$ Varios autores destacan las posibilidades de ese auge de la quina o cascarilla, tanto desde el siglo XIX (Quijarro, 1885), como en la historiografía actual (Jáuregui, 1991. Pérez, 2003: 103. Shchelchkov, 2011: 39). 
«está fuera del alcance de la clase menesterosa, que en América, como en todas partes, es siempre la más numerosa. Las minas enriquecen a los individuos, pero no a los pueblos», por los que la especialización en la exportación de recursos minerales había provocado, provocaba y seguiría provocando la pobreza de la población ${ }^{68}$.

El país, para Frías estancado ${ }^{69}$, estaba obligado a priorizar la salida atlántica. El porvenir de Bolivia «asoma en el oriente: en esa preciosa porción de territorio que se estiende [sic] desde el Beni hasta la Asunción, cuya parte septentrional está regada por ríos caudalosos i navegables que llevan sus aguas al Amazonas, cuyo centro alcanza hasta el gran río Paraguai, i cuya estremidad [sic] sud llega hasta la márjen [sic] izquierda del Pilcomayo» ${ }^{70}$. De ahí la citada y necesaria comprobación de esa supuesta navegabilidad fluvial por parte de la Administración, con resultados dispares. José Agustín Palacios fue el único que pudo completar la expedición que se le encomendó, en el Beni, el Madera y el lago Rogo-aguado, mientras que tanto los citados Magariños y Van Nivel no pudieron proseguir ${ }^{71}$, bien por la hostilidad indígena, bien por el bajo cauce del Pilcomayo que hizo imposible la navegación, algo que confirmó poco después Hughes A. Weddell en su paso por el $\mathrm{Chaco}^{72}$.

Frías consideró que el valor del premio justificaba los riesgos implícitos para abrir vías de navegación hasta allí, y por ello los obvió, aun conocerlos. Citaba a d'Orbigny con su promesa de que esas tierras podrían proporcionar ingentes cultivos de coca, caña, café, cacao, algodón y morera, así como oro fluvial, y grandes extensiones proclives a la ganadería, a lo que sumaba un llano terreno que convertiría en fáciles las comunicaciones internas con caminos de herradura o aprovechando las lluvias e inundaciones estacionales, además de las externas por el cauce de los ríos. La facilidad en la circulación de bienes era para Frías de suma importancia, dada la necesidad de superar al Pacífico, y por ello se atrevió a compartimentar el comercio boliviano, considerando que los

... departamentos del Beni, la Paz i Santa-Cruz están en relación inmediata con el Beni, el Mamoré i los demás ríos tributarios del Madera. La provincia de Chiquitos

${ }^{68}$ Frías, 1846: 4.

${ }^{69} \mathrm{La}$ insistencia en el estancamiento económico del país podía darse por una conjunción entre las condiciones reales de este y una voluntad de recentrar los ejes económicos que habían dominado la economía boliviana desde la independencia, básicamente, el eje paceño (Barragán, 2009: 42-43), hacia la oportunidad oriental.

${ }^{70}$ Frías, 1846: 5.

71 Palacios coincidía con Frías en señalar la idoneidad de la salida hacia el Atlántico por los Orientes, mientras que Magariños y Van Nivel, víctimas de fracasos en sus expediciones, no pudieron ser tan optimistas (García Jordán, 2001: 259-261).

${ }^{72} \mathrm{Su}$ expedición, terrestre, ha sido reeditada en Weddell, 2018. 
en el departamento de Santa-Cruz tiene además el Jaurú i los otros brazos orijinarios [sic] del Paraguai. Cochabamba por su posición central entre la Paz i Santa-Cruz podría valerse de las vías de ambos departamentos para comunicarse con los ríos, que cruzan en opuestas direcciones las provincias de Mojos i Chiquitos ${ }^{73}$.

Frías aventuraba que cada departamento dispondría de su propia salida al Atlántico, llegando a proyectar conexiones directas con los asentados en el Altiplano, como Cochabamba y La Paz, a través de sus Orientes. Hechas estas consideraciones, la vía por él considerada garantía de éxito era la del río Paraguay, en su cauce o por sus afluentes Pilcomayo y Bermejo ${ }^{74}$.

Sabiendo al donde, Frías pasó al cómo. El siguiente punto que consideraba fundamental y que introducía la idea del proyecto católico-industrial era el poblamiento de la región a partir del sometimiento indígena, por un lado, y de la inmigración, interior y exterior, por el otro. En su parecer, las tierras orientales si bien prometedoras económica y comercialmente por sus condiciones climáticas, geográficas y edáficas y por las proyecciones de los teóricos, carecían de habitantes más allá de los localizados grupos de indígenas descendientes de los reducidos por los Jesuitas, los no sometidos y los pocos colonos que se encontraban en el territorio, como d'Orbigny y Dalence coincidían en señalar ${ }^{75}$.

Mientras la primera solución a ese «despoblamiento» residía en conseguir que los pobladores ya existentes en la zona se incorporaran a las actividades productivas, la segunda consistía en fomentar la colonización a partir de la inmigración interior y la tercera en la llegada de población extranjera a la región. En relación con la primera, Frías subrayaba «la necesidad de someter a la obediencia de las autoridades bolivianas a las tribus numerosas, que habitan el Chaco septentrional (que es el de Bolivia), i que hoi [sic] viven independientes de todo gobierno civilizado ${ }^{76}$. Contradiciendo al expedicionario Magariños, que expuso en su diario sendas dificultades con los indígenas ante su carácter guerrero ${ }^{77}$, Frías veía a estos como fáciles de someter a partir de

${ }^{73}$ Frías, 1846: 6-7.

74 Ibidem: $7-9$.

75 d'Orbigny, 2004 y Dalence, 1851: 2, donde el boliviano considera que las tierras más fértiles de los Orientes están «despobladas e incultas», siendo de dos veces el tamaño de la Francia.

${ }^{76}$ Frías, 1846: 10.

77 Diario de navegación del río Pilcomayo por el General Manuel Rodríguez Magariños, 1844 y el Informe de viaje de Enrique N. Van Nivel por el río Pilcomayo, 1844, Archivo de la Casa de la Libertad, Sucre. Los movimientos de resistencia de las poblaciones chaqueñas, aunque frecuentemente invisibilizados por la historiografía, han sido trabajados por varios autores, negando ese pacifismo incuestionable que les otorga Frías (Langer, 1994b: 82-103. Combès, 2005: 227). 
prebendas que los llevaran a aceptar el orden católico y la vida industrial. Urgió así la necesidad de seguir con ese proyecto, ya que «la conquista del Chaco es indudablemente de fácil ejecución: i es tanto más urjente [sic] i glorioso acometerla, cuanto que Bolivia está obligada a ello no solo por las exijencias $[s i c]$ de su comercio i de su industria, sino además por el deber moral que pesa en la conciencia de los gobiernos americanos, de salvar de la barbarie a esas grandes porciones de hombres ${ }^{78}$. A ello, debía añadírsele la idoneidad de los mojeños para con el proyecto, quienes tenían en ellos la inquietud industriosa trasladada por los Jesuitas en la fabricación de tejidos ${ }^{79}$.

Como segunda solución para el fomento de la inmigración interior Frías apostaba por una colonización dirigida por el Gobierno desde el Altiplano a las Tierras Bajas. En este sentido, las colonias militares fueron el elemento que debía permitir a Ballivián colonizar los Orientes al mismo tiempo que dar salida al excedente militar existente ${ }^{80}$ desde el gobierno de Andrés de Santa Cruz y la guerra contra Gamarra ${ }^{81}$. Las «costumbres escesivamente [sic] hospitalarias $\mathrm{i}$ sus hábitos laboriosos $»^{82}$ de los indígenas deberían permitir el traslado de población de occidente a oriente.

Sin embargo, Frías consideraba ambas opciones — sometimiento de la población indígena e inmigración interior- insuficientes, tanto por la falta de población local y la dificultad para convertirla en pobladores productivos, como por el desinterés de los bolivianos en trasladarse a los Orientes ${ }^{83}$. La propia experiencia había mostrado la incapacidad de llevar a término un proyecto de colonización interna, como fue el que, durante la presidencia de Santa Cruz, desarrolló Manuel Luis Oliden. Contagiado del entusiasmo de d'Orbigny, Oliden consiguió una concesión generosa por parte del Estado de

78 Frías, 1846: 11.

${ }^{79}$ Ibidem: 12. Algo que trató de controlar el gobierno de Ballivián para una mayor efectividad de la imposición. "Decreto de 24 de mayo de 1845. «Tarifa para las producciones del Beni. Recaudación de la contribución indigenal de allí»”, Colección Oficial de Leyes..., 1858

${ }^{80}$ Coincido con García Jordán (2001: 272) en señalar la equivocación de Groff Greever (1987: 170), que considera las colonias militares como una medida transitoria y coyuntural. Para Ballivián fue un pilar notable de cara a la conquista de los Orientes y para la reforma militar, y la numerosa reglamentación que la acompaña es una prueba de ello.

${ }^{81}$ En la administración de Andrés de Santa Cruz eran conscientes de tal excedente, y aún instar al gobernante a tomar medidas pertinentes, como la licencia de soldados, las constantes guerras impidieron limitar el excedente de tropa. Véase Atanasio Hernández a Andrés de Santa Cruz, 7 de diciembre de 1837, Archivo Virtual Histórico del Mariscal Santa-Cruz, La Paz.

${ }^{82}$ Frías, 1846: 12.

${ }^{83}$ Groff Greever (1987: 171) descarta también la posibilidad de que el trabajo esclavista pudiera haber cambiado las cosas, precisamente por esa falta de población a la que esclavizar habiendo sido abolida la trata. 
tierras alrededor del río Otuquis, afluente del Paraguay, pero los problemas diplomáticos con el cierre del río por el presidente Francia condenaron su proyecto $^{84}$. Estas trabas habían desaparecido, pero las notas de Oliden mostraban cierta dificultad en la navegación de ese río, que aunque fue citado por Prudencio como una posible vía comercial ${ }^{85}$ no fue mencionado por Frías ${ }^{86}$.

La tercera solución fue la captación de población foránea. Frías preveía que sería exitosa, ya que «la relación en que se encuentran en Francia i en Inglaterra la población con el país habitado, vemos que la primera tiene 1.200 habitantes por legua cuadrada i la segunda cerca de 1.500; i podemos deducir que las solas provincias de Mojos i Chiquitos en Bolivia, atendida la fertilidad i la estensión [sic] de su suelo, podrían alimentar una población de la mitad de la Francia» ${ }^{87}$. La colonización europea, que estaba haciendo de los Estados Unidos un modelo de éxito en la conquista del Oeste, era la solución de los problemas orientales: la evangelización, la falta de industria, la apertura de vías de comercio y la población. Para ello, Frías señala en su escrito dos proyectos especialmente significativos.

El primero era el contrato firmado con un grupo irlandés para la colonización de los Orientes, sobre el que se les instruía a subir por el Madera hasta Mojos, o por el Paraguay hasta Chiquitos, llevando por si mismos buques de vapor y los medios necesarios para conducirlos hasta donde tuviera que establecerse un puerto. El segundo, más conocido, también estaba dirigido a esos mismos lugares pero, esta vez, con una compañía belga que había mostrado progresos mandando colonos a Santa Catalina, en Brasi ${ }^{88}$. La condición católica tanto de Bélgica como de Irlanda no debe pasarse por alto y Frías la destacó, ya que, aun no ser «partidario de la intolerancia en nada [...] concibo sin embargo que la diversidad de cultos en las masas de pueblos nuevos es un inconveniente» ${ }^{89}$. Opinaba que debían «cerrarse las puertas de un país americano al estranjero [sic] que disiente de la relijión [sic] dominante», pues «¿Cómo podrían moralizarse los indios de Bolivia, asimilándose a la raza civilizada, desde que los misioneros de creencias distintas los arrastraran en opuestas direcciones? $\gg^{90}$. La diversidad interna del cristianismo era

${ }^{84}$ Quijarro, 1885.

85 Prudencio, 1842b: 22.

${ }^{86}$ Hubo nuevos intentos de retomar el proyecto, con una prórroga en 1844, pero fueron todos frustrados, fuera por falta de interés estatal, conflictos diplomáticos o dificultades propias de la magnitud de este (García Jordán, 2001: 271. Fifer, 1972: 170-175).

87 Frías, 1846: 12.

88 Ibidem: 12-13.

${ }^{89}$ Ibidem: 14.

90 Idem. 
vista como una amenaza para la credibilidad del mensaje civilizador, que debía coincidir con el del propio gobierno; al ser este católico, tal era la religión que propagar. Si bien los colonos no tendrían la obligación expresa de evangelizar, Frías consideraba inevitable que lo hiciesen a través del contacto directo y constante con los pueblos indígenas, $\mathrm{y}$, en su proyecto, fue precisamente eso lo que permitiría la resolución de los problemas económicos, comerciales y demográficos de los Orientes, y no al contrario. El argentino continuaba en su relato católico-industrial, obviando las estructuras eclesiásticas del país por su necesidad de reforma y considerando la inmigración católica como su sustituto.

Paralelamente, Frías sostenía la necesidad de contar con los misioneros para la civilización de las poblaciones indígenas, porque sin «el auxilio de las misiones jesuíticas, las empresas de colonizar el Chaco fracasarían siempre, no solo por la inhabilidad de los que no profesan la predicación del Evanjelio [sic] para penetrar pacífica i gradualmente en la conciencia i los dominios de los salvajes, sino por el espíritu investigador que tanto distinguió a esos misioneros, de quienes son la mayor parte de las relaciones que se tienen sobre el mismo Chaco ${ }^{91}$. En consecuencia las misiones católicas debían ser la punta de lanza de la civilización ${ }^{92}$.

Aunque en la «Nota» se sostenía de forma sintética el cuerpo del proyecto católico-industrial que Frías pretendió para Bolivia, este texto no fue el único intento de influir en la opinión pública ni en la política del país. El importante periódico La Época, fundado por exiliados argentinos en 1845 en $\mathrm{La} \mathrm{Paz}^{93}$, fue un adalid de las ideas del argentino. El diario trató de crear un estado de opinión que obligara al Ejecutivo a continuar y profundizar el giro a los Orientes tomando al proyecto católico-industrial como guía. En su primer año, consideró en sus páginas que, en veinte años de independencia, «la condición miserable del Indio no ha mejorado casi nada, a pesar de las leyes y de la voluntad de los gobiernos»; la razón, que

... a la independencia no se ha seguido para el indio una época de ilustración, y pesa aún sobre su frente el velo negro de la ignorancia y del más consumado barbarismo. El indio que no conoce el derecho de propiedad, menos alcanza a comprender lo que le importa la ley de igualdad $^{94}$.

91 Ibidem: 14-15.

92 Como afirma García Jordán (2001: 288. García Jordán y Sala i Vila, 1998: 15) durante la administración de José Ballivián se reanudó la fundación de misiones y se hicieron avances, básicamente, en la zona del Chaco.

93 Unzueta, 2000: 63.

94 “Los indios y sus opresores", La Época, La Paz, 22/7/1845: 1. 
Los pueblos indígenas, esclavos de su propia ignorancia, debían ser liberados a partir de los «principios religiosos que aconseja la caridad cristiana» para formar en ellos un espíritu liberal y, por extensión, la inquietud industrial ${ }^{95}$.

El papel de la Iglesia también fue tratado en diversos artículos en el periódico. En el apartado de correspondencia se recogió un texto en mayo de 1845 , ejemplo de algunos otros en el mismo sentido, que señalaba que

... en el corazón de Bolivia vejeta un pueblo, que es parte integrante del pueblo boliviano, y que inmoble y sin una señal de vida es el escarnio de la Época y el más ingrato espectáculo para la República. Los indíjenas [sic], [son] los pagadores de casi la mitad del tesoro nacional ${ }^{96}$.

Y, aun así, considerados «Bestias de carga». Por ello, siempre según el escrito, deberían ser sacados de su lamentable situación por párrocos que los condujeran «con el amor e interés que inspira la caridad evanjélica $[s i c] »$. No obstante, resurge la incapacidad de la Iglesia para hacerlo:

¿Puede racionalmente esperarse que nuestros párrocos corijeren [sic] la condición del indíjena $[\mathrm{sic}]$ y que lo dispongan a la noble existencia que debe caberle en suerte al quedar ensayada la organización jeneral [sic] de la República? Nada menos que eso-Bolivia aún no ha podido ocuparse de la creación de su Iglesia ${ }^{97}$.

Se insistía en «que la humanidad y la civilización se interesan en la suerte de nuestro pueblo indígena; y que era ya llegado el tiempo de propender a su adelantamiento y al cambio de su degradante condición ${ }^{98}$ a través de la acción estatal y de una Iglesia verdaderamente liberal para el progreso del país. La intertextualidad con Frías, miembro fundador del periódico, es innegable; la prensa fue así otro vector de influencia del argentino para con el proyecto católico-industrial, que aun así encontró varias resistencias. Dichas ideas fueron bien conocidas por los poderes fácticos del Estado a partir de los numerosos encuentros de Frías con altos cargos del país en la hacienda de José Ballivián en Cebollullo ${ }^{99}$, por la incidencia en la incipiente prensa no

95 Ibidem: 2.

96 “Indios-Y curas párrocos”, La Época, 31/5/1845: 2.

97 Idem.

98 "Humanidad", La Época, 15/9/1845: 3.

99 En Cebollullo se hacían, en presencia de Ballivián, el dueño, tertulias durante su presidencia, así como fiestas campestres, donde los exiliados argentinos, como Mitre, Paunero o Frías, eran asiduos. El mismo Mitre escribió allí una novela, Soledad (Carrasco, 1960: 112 121). Hoy en día está en ruinas. 
oficial ${ }^{100}$, por los escritos aquí analizados o por su correspondencia ${ }^{101}$. De ello, se puede extraer que la intertextualidad entre ellos y la legislación analizada en el siguiente acápite no fue casual, siendo proyectos paralelos con influencias cruzadas.

\section{EL GIRO A LOS ORIENTES}

En este apartado se trata de mostrar la interconexión entre la obra de Frías y una parte significativa de las políticas de la Administración de José Ballivián, referente a lo que se ha llamado en este artículo como «giro a los Orientes» o el movimiento de la frontera económica boliviana hacia las Tierras Bajas «no conquistadas» por la civilización, el mercado interno, el ejército y la Administración. El objetivo es incidir en el argumento de las influencias cruzadas en la década de 1840 que se defiende en este artículo.

La base del proyecto católico-industrial de Frías fue la relación entre el cristianismo católico y el trabajo, la industria. Idea esta compartida y asumida prontamente por la Administración Ballivián que, cuando en 1841 decretó la necesidad de formar colonias militares como instrumentos para la expansión de la frontera social y económica en el Beni y Santa Cruz, señaló que «Los edificios públicos, como son, la Iglesia, escuela para la instrucción primaria, $[\ldots]$ se trabajarán con preferencia y en común por todos los colonos» ${ }^{102}$. De la acción legislativa se puede extraer el recelo del Gobierno hacia una Iglesia que, como consideraba Frías, era necesitada de reforma.

En ese sentido fue la acción de la Administración que, sin haber conocido cambios trascendentes en el organigrama eclesiástico, evitó un monopolio de la Iglesia sobre las mentes indígenas ${ }^{103}$. Conociendo la incapacidad temporal de la Iglesia para la aplicación de preceptos liberales, pero sin obviar la im-

100 Un brazo más de la influencia de los exiliados unitarios argentinos en la Bolivia de Ballivián (Carrasco, 1960. Blumenthal, 2015).

${ }^{101}$ Aunque no analizada en este artículo, parte de su correspondencia está presente en el citado Archivo del Museo Bartolomé Mitre, sito en Buenos Aires, que contiene muchas cartas, ante todo discusiones de geopolítica y diplomacia, con otro exiliado argentino, Domingo de Oro, y con José Ballivián.

${ }_{102}$ Como edificios separados, pero ambos regentados por los religiosos. Véase: "Decreto de 22 de noviembre de 1841. «Formación de colonias militares»", Colección Oficial de Leyes..., 1858.

${ }^{103}$ Lo que marca un claro paralelismo con la supresión del clero regular llevado a cabo por la administración Sucre, «por los precedentes de total relajación [moral] en que habían caído» ese tipo de religiosos. Lofstrom, 2011: 162. 
portancia de la religión católica, podemos observar cómo en 1844 el gobierno de Ballivián tomó otra vía para la obtención de los mismos resultados —es decir, la evangelización para la propagación del ideario liberal y la inquietud industriosa - ordenando abrir un registro en la policía para aquellas personas que quisieran acoger y educar nativos en sus casas. Ya que «está en los intereses de la humanidad y de la República, promover la civilización de las hordas salvages [sic], que van errantes y sin provecho propio, sobre un terreno inmenso cuya fertilidad convida a la producción», siendo por lo tanto un obstáculo para el avance de la agricultura, y «que subsistiendo solamente del robo, inquietan constantemente las provincias con que colindan», por lo que también su presencia tiene afectaciones a los derechos de propiedad, se consideró «que la trasmigración de esos seres desgraciados, es el medio más conforme con los principios de la religión cristiana y de la moderada política del gobierno de la República» ${ }^{104}$. Los particulares podrían acoger en sus casas a indígenas a los que utilizarían en el cultivo de tierras y el servicio doméstico, comprometiéndose, por su parte, a «1. ${ }^{\circ}$, a vestirlos y alimentarlos en igualdad que a sus demás domésticos: $2 .^{\circ}$, enseñarles la doctrina cristiana y hacerlos bautizar dentro de un año de haberlos recibido: $3 .^{\circ}$, a no tratarlos mal, ni de otro modo que a los otros sirvientes: $4 .^{\circ}$, a hacerles enseñar siendo adultos, algún arte u oficio» ${ }^{105}$. De este modo, se propagaría el ideario civilizador del cristianismo y se haría seguir el camino de la industria a esos «seres improductivos», evitando los problemas que estaban causando a los pioneros de la producción y el comercio en las Tierras Bajas, sin dar un poder adoctrinador excesivo a la Iglesia.

La orden aquí citada fue anterior a la publicación de «El cristianismo católico». No obstante, la intertextualidad entre la legislación y el escrito de Frías es notable en la toma de la religión como punta de lanza de la civilización para fomentar la industria en las regiones «salvajes» ${ }^{106}$ de América y, por extensión, de Bolivia ${ }^{107}$, pretendiendo así cambiar la mentalidad de los indígenas «salvajes». La influencia pública del autor fue presente desde el inicio de su exilio argentino, expuesta parcialmente en la prensa boliviana y al propio Ballivián en sus numerosas tertulias políticas en la

104 "Orden de 18 de septiembre de 1844. «Registro que ha de abrirse en la policía, para los que quieran tener y educar salvajes»”, Colección Oficial de Leyes..., 1858

105 Idem.

106 Concepto extendido temporal y espacialmente por la Latinoamérica decimonónica, que encierra en sí intenciones político-sociales claras; un ejemplo de trato del término en Navarro Floria, 2001.

107 García Jordán y Sala i Vila, 1998: 15. 
hacienda de Cebollullo ${ }^{108}$. Órdenes como la citada trataban de sobrellevar esa «incapacidad liberal» de la Iglesia para conseguir los mismos efectos de evangelización propuestos por Frías, sin la interacción directa con las estructuras eclesiásticas del momento, vistas con desconfianza también por el Ejecutivo, que tomó como suyas las reservas del argentino.

También es coincidente la vía preferencial de penetración a los Orientes. Ballivián trató de fomentar la exploración del Pilcomayo a partir de expediciones como las señaladas en el acápite previo, que antes fueron acompañadas del reconocimiento de la República del Paraguay y el establecimiento de las relaciones diplomáticas correspondientes, hasta entonces inexistentes. Es sabido que el gobierno del Dr. Francia mantuvo al Paraguay en completo aislamiento e impidió el comercio por el río, imposibilitando la llegada desde Bolivia al Plata ${ }^{109}$. A su muerte, ese país mostró un deseo expreso de apertura con sus nuevos gobernantes, y en la propia ley de reconocimiento se habla de «los deseos de cultivar con él las relaciones de amistad, comercio, navegación, y todas las que tiendan a la prosperidad» de ambos países, prorrogando el problema de delinear una frontera poco definida $^{110}$.

Si la orden para acoger y educar nativos en casas particulares podía responder a la vía de conquistar los Orientes gracias a la evangelización de los pueblos indígenas, Ballivián también puso empeño en la inmigración interior y exterior. Sobre la primera, tiene notoriedad la importancia que se quiso dar a las colonias militares. El objetivo de estas era claro pues considerando que «es obligación del Gobierno fomentar la industria, procurar por cuantos medios pueda el aumento de la población y la fundación de establecimientos útiles y provechosos a la República», el gobierno aprobó la creación de las «colonias militares, que se establecerán en las fronteras de los bárbaros, en las márgenes de ríos navegables, y en los campos de los fértiles y poco poblados valles que tiene la República» ${ }^{111}$. El éxito de las colonias militares fue cuestionable, como demuestra una resolución de 1845, donde se permite a los militares que se les hubiera adjudicado terrenos baldíos en esas colonias su venta sin tener necesidad de cultivar o siquiera visitar esas tierras, o vender

108 Carrasco, 1960: 115-123.

109 Areces, 2003.

110 "Ley de 17 de junio de 1843. «Reconocimiento de la República del Paraguay»", Colección Oficial de Leyes..., 1858.

111 "Decreto de 22 de noviembre de 1841. «Formación de colonias militares»", Colección Oficial de Leyes..., 1858 
el propio derecho de tener terrenos a adjudicar ${ }^{112}$. Lo importante en este caso es que en el discurso Ejecutivo subyace otro; en su intencionalidad aparece el relato de Frías de expansión del catolicismo y la frontera económica.

Sobre la segunda, el proyecto citado por Frías de colonización belga se consideró de importancia capital. Fue muy debatido en el Congreso, que aprobó el proyecto imponiendo severas condiciones ${ }^{113}$, y pautó sus objetivos:

Primero: Desarrollar la agricultura, la industria y el comercio en las diferentes provincias de Bolivia. Segundo: Establecer puertos, y extender (...) las relaciones comerciales entre las diversas provincias de Bolivia en el interior, y con los Estados vecinos y con la Europa en el exterior. Tercero: Establecer lo más pronto posible, comunicaciones regulares entre el Atlántico y Bolivia, por medio de un servicio de navegación de vapor (...). Cuarto: En fin, extender los recursos respectivos de las diferentes provincias, desarrollar el crédito de cada una de ellas en particular, y el de Bolivia en general, y asegurar la existencia, y el porvenir de los indígenas y colonos, asociando la propiedad al capital y al trabajo ${ }^{114}$.

Objetivos todos ellos que gracias a la llegada de la inmigración europea debía permitir el asiento de los ideales liberales de propiedad y trabajo entre los indígenas, que compartirían territorio con los recién llegados. El proyecto inmigratorio no pasaba por propiciar solamente la industria - el segundo pilar de la civilización propuesto por Frías - , ya que la propia procedencia de estos europeos sostiene que el primer pilar — la religión o la evangelización - era tomado en cuenta por el Gobierno.

En relación con estas ideas, detectamos en los debates en el Congreso cierta resistencia al proyecto abanderado por el Ejecutivo. Efectivamente, el diario de debates muestra la importancia que tuvieron los avances logrados en la navegación de los ríos interiores, en particular en el Pilcomayo y la zona del Otuquis ${ }^{115}$, al tiempo que se discute sobre la eventual presencia de inmigrantes no católicos en las Tierras Bajas ${ }^{116}$. No obstante, es significativo que

112 "Resolución de 6 de septiembre de 1845. «Aprueba la venta del derecho que tienen algunos licenciados del Ejército, para que se les adjudiquen terrenos baldíos»", Colección Oficial de Leyes..., 1858.

113 Como se discutirá en las siguientes páginas. "Ley de 12 de noviembre de 1844. «Aprobación condicional del tratado belga»", Colección Oficial de Leyes..., 1858.

114 "Decreto de 10 de diciembre de 1844. "Aprobación condicional del tratado de colonización belga»", Colección Oficial de Leyes..., 1858.

115 Redactor del H. Congreso Constitucional del año 1844, 1924: 98.

${ }^{116}$ El debate subió de tono en cuanto el diputado Eusebio Guilarte propuso que en el Beni se permitiera el culto público de cualquier otra religión que no fuera la católica, creyendo «que sería este un medio de promover la población, atrayendo a los extranjeros a este punto, sea cual fuere su creencia religiosa». Aunque fue una propuesta aprobada, no se le dio recorrido. Redactor de la Convención Nacional del año 1843, 1926: 182-183. 
uno de los debates que implicó más sesiones en época de Ballivián fuera sobre el tratado con la Sociedad Belga de Colonización. El Congreso negó varios de los beneficios que el enviado del Gobierno a Inglaterra, Vicente Pazos Kanki, había firmado con esa sociedad belga, por orden del Ejecutivo y con la alabanza de Frías, para emprender la colonización del Beni, la instalación y mejora de puertos fluviales y la evangelización de los pueblos indígenas ${ }^{117}$. El diputado Rafael Bustillos resumió la posición de la mayoría del poder legislativo considerando que, si bien el «resultado de este convenio verdaderamente sería útil a la República y ella reportaría ventajas de progreso en la industria, el comercio, las luces, la agricultura, etc.», eso solo sería posible en el caso de que «las condiciones que aparecen en él, no fueran tan onerosas y quizás perjudiciales en cierto respecto a los mismos intereses de Bolivia» ${ }^{118}$. Pragmático, el Congreso destacó el fracaso en la aplicación del modelo colonizador, para el que «sin embargo del interés que tomó y de un entusiasmo raro nada se ha conseguido. Esperamos pues; más nunca vendrán, esto es lo que se quiere promover y aprovechar de las invitaciones que se han hecho al gobierno» ${ }^{119}$.

En liza con el poder legislativo, el Ejecutivo no solo coincidió con el proyecto católico-industrial de Frías en sendos decretos y propuestas, pues también lo hizo en materia discursiva. El Ministro del Interior quiso destacar en su memoria de 1844 la presencia de expediciones en el Beni, el Otuquis y sobre todo el Chaco, así como anunció un acuerdo con empresarios de la Guyana Francesa para la colonización del lago Rogo-aguado ${ }^{120}$. Ese mismo año se dio la potestad al Ejecutivo de patrocinar la colonización extranjera y paralelamente reclutar «a los habitantes que existen o existieren en las márjenes [sic] del Pilcomayo i del Bermejo, recayendo esta gracia hoi [sic] en favor de bolivianos existentes en esas comarcas i de los estranjeros [sic] que allí se sitúen ${ }^{121}$. Conviene señalar que junto a esos proyectos, el gobierno Ballivián había aprobado medidas destinadas a la implementación de la educación pública en los Orientes, como en 1843 afirma el Ministro de Instrucción Pública, estableciendo escuelas «en las fronteras de los bárbaros para

117 Redactor del H. Congreso Constitucional del año 1844, 1924: 255-259.

118 Ibidem: 268.

119 Ibidem: 272. El Congreso se mostraba más proclive a encontrar soluciones al problema monetario, por la acuñación de moneda feble con intención fiscal (y con el contrabando de plata resultante de ello, por no pagar su rescate en moneda fuerte) (Prado Robles, 1997: 12-15), que no a nuevas inversiones de resultado incierto, como suponían los Orientes.

${ }_{120}$ Buitrago, 1844: 12. No hay constancia de que llegaran a colonizarse los territorios adyacentes al lago por tal empresa.

121 Guerra, 1846: 5-6. 
extender nuestras conquistas por aquellos puntos por el medio de la civilización» que el catolicismo y el pensamiento liberal propiciaban ${ }^{122}$.

En suma y vistos los resultados, consideramos que el proyecto de Frías influyó en el que protagonizó la Administración de José Ballivián en su giro a los Orientes. La voluntad de promocionar la expansión del catolicismo en Tierras Bajas para el progreso económico de éstas entró en conflicto con el poder legislativo, que no compartió el discurso. Este poder puso trabas a propuestas de Ballivián como el tratado de colonización belga, discutió el monopolio religioso católico y vio con escepticismo que las políticas promulgadas por el Ejecutivo, coincidentes con el ideario de Frías, tuvieran alguna posibilidad de éxito. Sin embargo, ello no invalida la relación existente entre el proyecto de Frías y el del Ejecutivo, y el campo de influencia discursivo que logró erigir en la opinión pública. Leer la obra de Frías de la década de 1840 puede ser un acercamiento al ideal pretendido por el gobierno de Ballivián con respecto a los Orientes bolivianos.

El giro a los Orientes de la administración Ballivián se basó en la necesidad de hallar una salida viable a la producción interna a través de los ríos que desembocaran en el Atlántico, la incorporación de las poblaciones indígenas a las actividades productivas y, paralelamente, el poblamiento de esos territorios con europeos que paliaran la baja demografía existente. El proyecto católico-industrial propuesto por Frías recogía todas estas cuestiones amalgamadas por el catolicismo liberal de Lamennais reinterpretado en el contexto boliviano. Ambos proyectos, tanto el de la administración Ballivián como el de Frías, se desarrollaron en paralelo, mostrando una intertextualidad tal que deben afirmarse influencias cruzadas, pero también con diferencias.

El argentino tomó el cristianismo liberal en pujanza en Europa como guía para construir uno de los varios proyectos que se dieron de este tipo en la Latinoamérica decimonónica. Hizo del catolicismo el primer pilar, conjunto de valores morales universales que propiciaba la interiorización del ideario liberal y, en consecuencia, el trabajo y la industria, segundo pilar del proyecto de Frías. Para Ballivián, en cambio, la cristianización era accesoria, parte del trayecto a recorrer para el éxito del proyecto civilizatorio ${ }^{123}$, pero no un fin del proyecto estatal. Los poderes fácticos del Estado estaban interesados en la promoción de la producción económica de los varios y abundantes recursos que los Orientes debían proporcionar al mercado interno y a la exportación, y eso se tradujo en una legislación que trataba de promocionar la

122 Méndez, 1843: 10-11.

${ }^{123}$ Una punta de lanza, como se ha señalado en la historiografía y repetido en esta exposición, por la visualidad del concepto (García Jordán y Sala i Vila, 1998: 15). 
población, el comercio y la «propagación de la civilización». Coincidiendo con el ideario del argentino, se desconfió de la «atrasada» y «antiliberal» Iglesia y se dio a la cristianización un papel que, de hecho, se incrementó en los gobiernos bolivianos sucesivos, por otras vías ${ }^{124}$. La hipotética importancia que debían tener las colonias militares, con el entramado legislativo que las reglamentó, y la insistencia fallida en la búsqueda de una inmigración de europeos a los Orientes ${ }^{125}$, aspiraban a ser los métodos correctos para la incorporación a la religión y producción de tales tierras, ambos sin éxitos notables fuera del papel, también por la velada resistencia del Congreso.

En el caso específico de la segunda de las obras analizadas ${ }^{126}$, se interpela directamente a la administración boliviana. Sin embargo, no debemos olvidar que se trata de la adaptación a la especificidad boliviana de «El cristianismo católico», una obra pensada para la totalidad de los países latinoamericanos. Frías partió de una intención transnacional, vinculada a su condición de exiliado político, buscando el fin último del progreso de todo el continente a través de la religión y el trabajo. Esta consideración no debe eclipsar tampoco la voluntad de Frías de cambiar el gobierno en Argentina y hacer carrera en la administración pública del país; la intencionalidad última es influir en la esfera pública argentina a partir de la legitimación que le proporcionaría su éxito en Bolivia ${ }^{127}$. Ballivián podía ser para Frías el trampolín legitimador que le permitiera ser - con razones de un peso más notable de las que ya podía aportar - una voz preponderante en el escenario argentino y que ayudara en la campaña abierta contra Juan Manuel de Rosas.

\section{REFLEXIONES FINALES}

En síntesis, cristianismo e industria debían ser para Frías las bases necesarias de la integración de los Orientes bolivianos a la civilización, propagada tanto desde el Gobierno boliviano, las gentes del Altiplano, y los inmigrantes europeos que, viviendo en malas condiciones en sus países, acudirían en masa a esas fértiles e incultas tierras. El discurso católico-industrial de Frías

${ }^{124}$ Como García Jordán (2001: 289-291; 2006: 138-143) demuestra, con una creciente presencia de misiones y evangelizadores a partir de la década de 1850, habiendo iniciado ese contexto de aumento de presencia religiosa el propio Ballivián.

125 Groff Greever, 1987: 63.

126 Frías, 1846.

127 Tesis que defiende el citado Blumenthal (2015), y a la que apunta con su sugerente título: «Lo que viene de afuera siempre vale más», refiriéndose a la legitimidad del discurso que otorgaba la experiencia transnacional. 
vivió influencias cruzadas con el giro a los Orientes de la Administración de Ballivián; permeó en el Ejecutivo boliviano en una practicidad que no finalizó en su mandato, consolidándose una constante búsqueda de las escondidas riquezas orientales. De hecho, la significación de esos territorios como tierras de promisión que caló en el imaginario regional en tiempos coloniales y recreó d'Orbigny ${ }^{128}$, y que fue de la que se valió Frías por un lado, y Ballivián por otro, para proponer la idoneidad de la política orientalista, se vio confirmada pocos años después en el estudio estadístico de José María Dalence ${ }^{129}$. Con ese bosquejo, el intelectual argentino y el presidente boliviano vieron legitimado por la ciencia estadística - fuera más o menos acertada - su discurso alrededor del porvenir oriental de Bolivia.

Las afirmaciones defendidas en este artículo deben llevar a la formulación de nuevas preguntas, como las raíces de las reticencias del poder legislativo con respecto a las riquezas de los Orientes, la posible recepción de los textos pan-americanistas de Frías en demás países del continente, la evolución del pensamiento e influencia sobre la opinión pública del catolicismo liberal europeo en Bolivia o la importancia real de las colonias militares en la Administración de Ballivián, que nuevos textos podrían responder en próximas investigaciones.

\section{BiBLIOGRAFÍA}

Areces, Nidia R., Estado y frontera en el Paraguay: concepción durante la dictadura suprema y perpetua del Dr. Gaspar Rodríguez de Francia, dirigido por José María Oliva Melgar, Huelva, Universidad de Huelva, 2003.

Arguedas, Alcides, Historia general de Bolivia: el proceso de nacionalidad, 18091921, La Paz, Puerta del Sol, 1967 [1922].

Arze Aguirre, René (dir.), El naturalista francès Alcide Dessaline d'Orbigny en la visión de los bolivianos, Lima, IFEA, 2002.

Aubert, Roger, Beckmann, Johannes, Corish, Patrick J. y Lill, Rudolf, History of the Church: The Church in the age of liberalism, Londres, Burns \& Oates, 1981.

Ayala Mora, Enrique (dir.), Historia general de América Latina, París, UNESCO, 2008, vol. VII.

Ballivián, José, Campaña de cuarenta días, hecha por el Ejército boliviano al mando de S.E. el Jeneral D. José Ballivián, contra el Ejército invasor del Perú a las

\footnotetext{
128 Arze Aguirre, 2002: 144. García Jordán, 2001: 252-254.
}

129 Dalence, 1851: 2. 
órdenes del Jeneralísimo de sus armas D. Agustín Gamarra, Sucre, Imp. del Colejio de Artes, 1841.

Barragán, Rossana, "Hegemonías y «Ejemonías»: las relaciones entre el Estado Central y las Regiones (Bolivia, 1825-1952)", Íconos. Revista de Ciencias Sociales, 34 (Quito, 2009): 39-51.

Blumenthal, Edward, “«Lo que viene de afuera siempre vale más»: exiliados argentinos entre Europa y América (1840-1855)", Jeanne Moisand, Delphine Díaz, Romy Sánchez Villar y Juan Luis Simal (eds.), Exils entre les deux mondes: migrations et espaces politiques atlantiques au XIXe siècle, París, Les Perséides, 2015: 251-266.

Borie, César, Castro, Victoria, Varela, Varinia y Aldunate, Carlos, “Cobija y sus vías de conexión con el interior de Atacama. Desde la colonia hasta la guerra del salitre", Diálogo Andino, 49 (Arica, 2016): 209-223.

Botta, Mónica, "Juan Bautista Alberdi y sus incursiones en la literatura dramática", Hispanófila, 167 (Chapel Hill, 2013): 65-77.

Buitrago, Pedro, Memoria que presenta a las Cámaras Constitucionales de 1844 el Ministro del Interior, Pedro Buitrago, Sucre, Imprenta de Beeche, 1844.

Bulmer-Thomas, Victor, La historia económica de América Latina desde la independencia, Ciudad de México, Fondo de Cultura Económica, 1998.

Bustamante, Ricardo José, A la gloriosa memoria del inmortal D. José Ballivián, Cochabamba, s/e, 1853.

Cajías, Fernando, La provincia de Atacama: 1825-1842, La Paz, Instituto Boliviano de Cultura, 1975.

Cajías, Fernando, "El norte y el sur de Bolivia: Arica y Cobija en los primeros años republicanos", Rossana Barragán, Dora Cajías y Seemin Qayum, El Siglo XIX en Bolivia y América Latina, La Paz, IFEA, 1997: 129-137.

Capellán de Miguel, Gonzalo, "El problema religioso en la España contemporánea. Krausismo y catolicismo liberal”, Ayer, 39 (Madrid, 2000): 207-241.

Carrasco, Manuel, José Ballivián, 1805-1852. Estampas históricas, Buenos Aires, Hachette, 1960.

Castelfranco, Diego, ¿Dios y libertad? Félix Frías y el surgimiento de una intelectualidad y un laicado católicos en la Argentina del siglo XIX, Rosario, Prohistoria, 2018 .

Castelfranco, Diego, "Félix Frías en Francia (1848-1855): El nacimiento de un «escritor católico» rioplatense", Historia, 2/52 (Santiago de Chile, 2019): 313-339.

Chartier, Roger y Sanchís Martínez, Marina, "El mundo como representación”, Historia Social, 10 (Alzira, 1991): 163-175. 
Colàs, Pol, "Auge y caída de Andrés de Santa Cruz y su Confederación: el «imperio de la traición» y la legitimación caudillista", Boletín Americanista, 79 (Barcelona, 2019): 47-67.

Colàs, Pol, “Auge y caída de José Ballivián en Bolivia (1841-1847). Construcción y derribo de la batalla de Ingavi como base legitimadora", Anuario de Estudios Americanos, 78/1 (Sevilla, 2021): 257-290.

Colección Oficial de Leyes, Decretos, Órdenes y Resoluciones Supremas que se han expedido para el Régimen de la República Boliviana, Sucre, Imprenta de López, 1858.

Combès, Isabelle, "Las batallas de Kuruyuki. Variaciones sobre una derrota chiriguana", Bulletin de l'Institut français d'études andines, 34/2 (Lima, 2005): 221-233.

Cortés, Manuel José, Ensayo sobre la historia de Bolivia, Sucre, Imprenta de Beeche, 1861.

Crespo, Alberto, Los exiliados bolivianos (siglo XIX), La Paz, Grupo Editorial Anthropos, 1997.

Dalence, José María, Bosquejo estadístico de Bolivia, Sucre, Imprenta de Sucre, 1851.

Demélas, Marie-Danielle, L'invention politique. Bolivie, Equateur, Pérou au XIXe siècle, París, Éditions Recherche sur les Civilisations, 1992.

d'Orbigny, Alcide, Descripción geográfica, histórica y estadistica de Bolivia, París, Imp. Lacrampe y Cía. / Librería de Gide y Cía., 2004, tomo I.

Fifer, J. Valerie, Bolivia: Land, Location and Politics since 1825, Cambridge, Cambridge University Press, 1972.

Frías, Félix, El cristianismo católico considerado como elemento de civilización en las repúblicas hispano-americanas, Valparaíso, Imprenta del Mercurio, 1844.

Frías, Félix, Nota dirijida a S.G. el señor Don Tomás Frías, ministro de Relaciones Exteriores de Bolivia, por Don Félix Frías, cónsul de la misma República en Chile, Valparaíso, Imprenta del Mercurio, 1846.

García Jordán, Pilar, Iglesia y poder en el Perú contemporáneo, 1821-1919, Cuzco, Centro Bartolomé de las Casas, 1991.

García Jordán, Pilar, Cruz y arado, fusiles y discursos. La construcción de los Orientes en el Perú y Bolivia, 1820-1940, Lima, IFEA / IEP, 2001.

García Jordán, Pilar y Sala i Vila, Núria (coords.), La nacionalización de la Amazonía, Barcelona, Publicacions Universitat de Barcelona, 1998.

Gelman, Jorge, Rosas bajo fuego. Los franceses, Lavalle y la rebelión de los estancieros, Buenos Aires, Sudamericana, 2009. 
Grinchpun, Boris Matías, “"La alternativa reaccionaria». Félix Frías y las raíces intelectuales de la derecha católica en Argentina (1852-1881)”, Oriol Luján y Laura Canalias (eds.), Los embates de la modernidad. Debates en torno a la ciudadanía, el liberalismo, el republicanismo, la democracia y los movimientos sociales, Barcelona, Universitat Autònoma de Barcelona, 2015, vol. IV: 161-180.

Groff Greever, Janet, José Ballivián y el Oriente boliviano, La Paz, Ed. El Siglo, 1987.

Guerra, Pedro José de, Memoria que el Ministro de Estado en el despacho de lo Interior presenta a las Cámaras Constitucionales de la República de Bolivia, Sucre, Imprenta de Beeche, 1846.

Guiteras Mombiola, Anna, De los llanos de Mojos a las cachuelas del Beni, 18421938, Cochabamba, Itinerarios Editorial / ABNB, 2012.

Habermas, Jürgen, Facticidad y validez, Madrid, Trotta, 1998.

Halperin Donghi, Tulio, Historia contemporánea de América Latina, Madrid, Alianza Editorial, 2013 (3. ${ }^{\mathrm{a}}$ ed.), [1969].

Huber Abendroth, Hans, "Comercio, manufactura y hacienda pública en Bolivia entre 1825 y 1870”, Rossana Barragán, Dora Cajías y Seemin Qayum, El Siglo XIX en Bolivia y América Latina, La Paz, IFEA, 1997: 305-346.

Irurozqui, Marta, “A bala, piedra y palo”. La construcción de la ciudadanía política en Bolivia, 1826-1952, Sevilla, Diputación de Sevilla, 2000.

Irurozqui, Marta, "El espejismo de la exclusión. Reflexiones conceptuales acerca de la ciudadanía y el sufragio censitario a partir del caso boliviano", Ayer, 70/2 (Madrid, 2008): 57-92.

Irurozqui, Marta, Ciudadanos armados de ley. A propósito de la violencia en Bolivia, 1839-1875, La Paz, Plural / IFEA, 2018.

Jáuregui, Juan H., Sorata: Historia de una región, 1870-1930, La Paz, Prefectura del Departamento de La Paz / UMSA / IFEA, 1991.

Langer, Erick D., "Mission Land Tenure on the Southeastern Bolivian Frontier, 1845 1949", The Americas, 50/3 (Cambridge, 1994a): 399-418.

Langer, Erick D., "Caciques y poder en las misiones franciscanas entre los chiriguanos en la crisis de 1892", Siglo XIX, 15 (Monterrey, 1994b): 82-103.

Langer, Erick D., "The Franciscan Missionary Enterprise in Nineteenth-Century Latin America", The Americas, 68/2 (Cambridge, 2011): 167-178.

Lema Garrett, Ana María, "Misioneros: mediadores entre indígenas amazónicos y el Estado (siglos XVIII-XX)", Ángel Eduardo Román-López Dollinger y María Beatriz Castro Mojica, Amazonía boliviana. Visibilizando la diversidad de los pueblos de Tierras Bajas, La Paz, ISEAT, 2016: 13-58. 
Letelier Cosmelli, Javiera, "Entre la costa de Cobija y Tierras Altas. El tráfico arriero a inicios de la República Boliviana", Diálogo Andino, 49 (Arica, 2016): 225-234.

Lofstrom, William, "Cobija, Bolivia's First Outlet to the Sea", The Americas, 31/2 (Cambridge, 1974): 185-205.

Lofstrom, William, La presidencia de Sucre en Bolivia, La Paz, Biblioteca del Bicentenario de Bolivia, 2011 [1983].

Maiguashca, Juan, "Capítulo VIII. El proyecto garciano de modernidad católica republicana en Ecuador, 1830-1875", Marta Irurozqui (ed.), La mirada esquiva. Reflexiones históricas sobre la interacción del Estado y la ciudadanía en los Andes (Bolivia, Ecuador y Perú), siglo XIX, Madrid, CSIC, 2005: 233-259.

Martínez, Françoise, "Los primeros pasos liberales hacia la unificación escolar en Bolivia”, Revista Historia de la Educación Latinoamericana, 1 (Tunja, 1998): 1-23.

Méndez, Manuel de la Cruz, Memoria que el Ministro de Instrucción Pública presenta a la Convención Nacional reunida en 1843, Sucre, Imprenta de Beeche, 1843.

Méndez Reyes, Salvador, "José Ignacio Víctor Eyzaguirre y las corrientes intelectuales de su época", Estela Morales Campos (et al.), América Latina: las caras de la diversidad, Ciudad de México, UNAM, 2006: 295-310.

Morelli, Federica, "Entre Ancien et Nouveau Régime. L'histoire politique hispanoaméricaine du XIXè siècle", Annales. Historie, Sciences Sociales, 4 (París, 2004): 759-781.

Myers, Jorge, "Ideas moduladas: lecturas argentinas del pensamiento político europeo", Estudios Sociales, 26 (Santa Fe, 2006): 161-174.

Navarro Floria, Pedro, "El salvaje y su tratamiento en el discurso político argentino sobre la frontera sur, 1853-1879", Revista de Indias, LXI/222 (Madrid, 2001): 345-376.

Palacios, José Agustín, Exploración de los ríos i lagos del departamento del Beni y en especial el Madera, La Paz, Imprenta Paceña, 1852.

Parkerson, Phillip T., Andrés de Santa Cruz y la Confederación Perú-Boliviana, 1835-1839, La Paz, Librería Editorial Juventud, 1984.

Paz Soldán, Edmundo, Alcides Arguedas y la narrativa de la nación enferma, La Paz, Plural Editores, 2003.

Peralta, Víctor, El poder burocrático en la formación del Estado moderno. Bolivia, 1825-1880 [tesis de maestría], Quito, FLACSO, 1992.

Peralta, Víctor e Irurozqui, Marta, Por la concordia, la fusión y el unitarismo. Estado y caudillismo en Bolivia, 1825-1880, Madrid, CSIC, 2000.

Pérez, Carlos, "El bandidaje político en la frontera de la Cinchona: el caso de Juan José Pérez". Guillermo Delgado y Josefa Salmón (eds.), Identidad, ciudadanía y participación popular desde la colonia al siglo XX, La Paz, Plural, 2003: 95-114. 
Plata Quezada, William, "El catolicismo liberal (o liberalismo católico) en Colombia decimonónica", Franciscanum. Revista de las ciencias del espíritu, LI/52 (Bogotá, 2009): 71-132.

Platt, Tristan, Estado boliviano y ayllu andino. Tierra y tributo en el Norte de Potosí, La Paz, Biblioteca del Bicentenario de Bolivia, 2016.

Prado Robles, Gustavo A., "Efectos económicos de la adulteración monetaria en Bolivia, 1830-1870", Rossana Barragán, Dora Cajías y Seemin Qayum, El Siglo XIX en Bolivia y América Latina, La Paz, IFEA, 1997: 277-304.

Prudencio, Julián, Reseña del estado ruinoso de Bolivia por un ciudadano, Sucre, Imprenta de la Libertad, 1842a.

Prudencio, Julián, Cuaderno segundo de la reseña del estado ruinoso de Bolivia por un ciudadano, Sucre, Imprenta de la Libertad, 1842b.

Quijarro, Antonio, Descripción de la nueva Provincia de Otuquis en Bolivia. Segunda edición corregida y aumentada por Mauricio Bach, secretario de la misma provincia con permiso del empresario, año de 1842, Buenos Aires, Imprenta de Jacobo Peuser, 1885.

Redactor de la Convención Nacional del año 1843, La Paz, Litografías e Imprentas Unidas, 1926.

Redactor del H. Congreso Constitucional del año 1844, La Paz, Litografías e Imprentas Unidas, 1924.

René-Moreno, Gabriel, José Ballivián, La Paz, Camarlinghi, 1970 [1894].

Rojas Castro, Braulio, "La insociable sociabilidad chilena. Tensiones entre potencia política e ingobernabilidad democrática. Reflexiones en torno a Francisco Bilbao", La Cañada, 5 (Santiago de Chile, 2014): 123-137.

Romero Carranza, Ambrosio, Vida y testimonio de Félix Frías, Buenos Aires, Academia Nacional de Derecho y Ciencias Sociales, 1995.

Roniger, Luis y Herzog, Tamar (eds.), The collective and the public in Latin America: cultural identities and political order, Brighton, Sussex Academic Press, 2000.

Serrafero, Mario D., “Alberdi, la Constitución y el régimen político de la Argentina”, Revista Acadêmica, 88/2 (Recife, 2016): 26-48.

Shchelchkov, Andrey A., La utopía social conservadora en Bolivia: el gobierno de Manuel Isidoro Belzu (1848-1855), La Paz, Plural, 2011.

Sierra, Vicente Dionisio, Historia de la Argentina, Buenos Aires, Editorial Científica Argentina, 1956, vol. I.

Sobrevilla Perea, Natalia, The Caudillo of the Andes: Andrés de Santa Cruz, Cambridge, Cambridge University Press, 2011. 
Soria, Claudia, "Sarmiento, Rosas y la ley del padre en «Facundo»", Hispamérica, 28/84 (College Park, 1999): 117-124.

Unzueta, Fernando, "Periódicos y formación nacional: Bolivia en sus primeros años", Latin American Research Review, 35/2 (Pittsburgh, 2000): 35-72.

Vicente Algueró, Felipe-José de, El catolicismo liberal en España, Madrid, Ediciones Encuentro, 2012.

Weddell, Hughes A., Viaje en el sur de Bolivia (1845-1846), Santa Cruz de la Sierra, Isabelle Combès / El País, 2018.

Fecha de recepción: 20 de julio de 2019.

Fecha de aceptación: 17 de marzo de 2020.

\section{Félix Frías and the turn towards the Bolivian Orientes of José Ballivián}

This text analyses what was known as the "Catholic-industrial" project of Argentine intellectual Félix Frias, in the context of influential Catholic liberalism in mid-nineteenth-century Latin America, in which spreading Catholicism to indigenous peoples was considered necessary to foster the liberal spirit among the neophytes. It is maintained that, given his exile in Bolivia and his proximity to the administration of José Ballivián (1841-1847), the new policies designed to integrate the Bolivian Orientes in the internal market carried out by Ballivia's government were both influenced by Frias's discourse and had an impact on it. Frias's thought was expressed primarily in two works, published in 1844 and 1846 respectively, which are one of the sources of this article, in addition to press articles, legislative debates, legislation and other documents, with a view to showing the intertextuality between Frias's work and Ballivián's policies.

Key words: Bolivia; Frias; Ballivián; nineteenth century; Orientes; indigenous peoples. 
